\title{
CARTOGRAFIA-ANANSE Territórios do axé na Tríplice Fronteira
}

CARTOGRAPHY-ANANSE

\author{
Axé territories in the Triple Frontier
}

\begin{abstract}
Marina Aureo Galdino
lyálorixá do lle Axé e do Afoxé Oju Ogun Funmilayol

Rede de Mulheres Negras do Paraná e Conselho Municipal de

Igualdade Racial de Foz do Iguaçu | Foz de Iguaçú, Brasil afoxefunmilaiyo@gmail.com | ORCID iD: 0000-0001-6502-0326

Maurício dos Santos

Universidade Federal da Integração Latino-Americana

Programa de Pós-Graduação Interdisciplinar em

Estudos Latino-Americanos | Foz de Iguaçú, Brasil medianeira.mauricio@gmail.com | ORCID iD: 0000-0002-7749-7604 Thiago de Azevedo Pinheiro Hoshino
Universidade Federal do Paraná

Programa de Pós-Graduação em Direito | Curitiba, Brasil hoshino.thiago@gmail.com | ORCID iD: 0000-0003-3261-6726
\end{abstract}

\begin{abstract}
Resumo
O tema da fronteira, como metáfora, como aposta metodológica ou como problema não está ausente da literatura sobre as religiões afro-brasileiras. Não obstante, existe uma lacuna sensivel entre o pensar fronteiras e o pensar fronteiriço, que assume a condição do front, da afronta e do afro como potência, fazendo da encruzilhada sua epistemologia. Trata-se, como o presente artigo propõe, a partir da dinâmica dos terreiros de Foz do Iguaçu/PR e dos movimentos do axé na Tríplice Fronteira, de uma vocação de caminhos do povode-santo e das agências que $o$ atravessam e constituem. Nessa nomadologia, Anansi, a fiandeira de histórias e mundos dos ashanti, é a melhor das cartógrafas e boiadeiros, orixás, exus e caboclos ensinam que, como a aranha, viver no santo é fazer seu próprio lugar, vivendo do que se tece.
\end{abstract}

\section{Palavras-chave}

Religiões afro-brasileiras; Ananse; Axé; Fronteiras; Espacialidades.

\begin{abstract}
The border, as a metaphor, a methodological approach or an issue is not absent from the literature on Afro-Brazilian religions. Nevertheless, there is a sensitive gap between thinking about frontiers and a frontier-based thinking that assumes the condition of the front, the affront and the afro as potency, making the intersection [encruzilhada] its epistemology. It consists, as this article proposes, drawing on the dynamics of the terreiros in Foz do lguaçu and the movements of axé in the Triple Frontier, of a vocation of paths of the povo-de-santo and the agencies that cross and constitute it. In this nomadology, Anansi, the spinner of stories and worlds of the ashanti, is the best of the cartographers, and the boiadeiros, orixás, exus, and caboclos teach that, like a spider, to "live in the saint" [viver no santo] means to make your own place, living from what you weave.
\end{abstract}

\section{Keywords}

Afro-Brazilian religions, Ananse, Borders, Axé, Spatialities. 


\author{
Sou aquele boiadeiro \\ aquele boiadeiro \\ morador de fronteira, \\ quando pego meu berrante \\ o meu gado vem ligeiro \\ (Cantiga do Caboclo Sete Laços \\ do Ile Axé Oju Ogun Funmilayo)
}

\title{
(En)cruzando (a)fronteiras
}

O tema da fronteira, como metáfora, como aposta metodológica ou como problema não está ausente da literatura sobre as religiões afro-brasileiras. Ele emerge, explícita ou tacitamente, na representação dos terreiros como comunidades diaspóricas de condensação geopolítica ${ }^{1}$, rearticulando fronteiras étnicas na estrutura da "família de santo" (Lima 2003); na posição liminar dessas tradições dentro e fora da "modernidade brasileira" (Carvalho 1999); na multilocalidade e transitividade de sua experiência entre o domínio dos viventes e dos ancestrais (Santos 2008); na composição de dinâmicas espaciais urbanas e rurais ${ }^{2}$ (Risério 2012) e de distintos modos de segmentação política (Goldman 2003).

Também no âmbito dos estudos transnacionais, têm-se enfatizado os "caminhos" globais da prática afro-religiosa, em itinerários que atravessam fronteiras administrativas e simbólicas (Oro 2013; Frijerio 2013; Beliso de Jesus 2015); a montagem transatlântica das "nações" de candomblé e de seus nacionalismos $^{3}$ (Matory 1999; 2015); os usos menos

\footnotetext{
1 "No terreiro operou-se uma síntese original: a reunião de cultos a orixás (e, também a voduns) que, na África, se realizavam em separado, seja em templos, seja em cidades; a condensação do próprio espaço geográfico africano nos dispositivos morfo-simbólicos da 'roça' (oká), outra palavra para 'terreiro' e que conota as comunidades litúrgicas como situadas no mato, fora do contexto urbano. Na condensação do terreiro, transpõe-se muito da concepção espacial contida na cosmovisão nagô" (Risério 2012: $158)$.

2 "Como o termo nativo "roça", relativamente comum, expressa: "Os templos em que se pratica o candomblé, embora sejam também conhecidos por esse termo, são mais comumente chamados de 'terreiro', 'roça', 'casa-de-santo', ou pelos termos de origem iorubana: ilê (casa), abassá (salão), axé (força vital) ou egbé (comunidade)" (Silva 2008: 96).

3 “(...) tenho argumentado que alguns dos grupos africanos e afroamericanos mais importantes são transatlânticos na sua gênese. (...) $O$ grupo étnico jeje é um desses casos que estende a duração do fenômeno cultural e politicamente transformador, que é atualmente chamado de "transnacionalismo". Não menos importante, esse caso demonstra que
} 
arborescentes do que rizomáticos ou, no mínimo, híbridos, da noção êmica de "raiz" (Meira 2017). De certa maneira, a fronteira (ou, provocativamente, na ambição teórica deste trabalho, afronteira) está aqui pulsante, atualizada a cada movimento dessas(es) (a)gentes cosmopolíticas(os), a um só tempo seus contestadoras(es) e produtoras(es).

Assim, inspiradas(os) por perspectivas que assumem a "encruzilhada" (Simas e Rufino 2018), a "linha cruzada" (Dos Anjos 2006) e o "entre-lugar" (Bhabha 2007) como valências epistemológicas, propomos um ingresso na produção social do espaço do povo de terreiro na Tríplice Fronteira (BrasilParaguai-Argentina) pelas teias de Ananse (a aranha historiadora dos ashanti). A partir de diálogos travados com religiosos/as, em trabalho de campo na cidade de Foz do Iguaçu, realizado no período de 2016 a 2018, por meio de etnografia no Ilê Axé Oju Ogun Funmilayó, acompanhamento de festas e celebrações públicas em espaços de natureza e em templos, e de entrevistas com autoridades religiosas de candomblé e umbanda, esboçamos uma interpretação sobre a territorialidade do axé e sua vocação caminhante: uma cosmopolítica urbana nômade.

\section{A aranha-cartógrafa e a teia urbana}

Desde o seminal trabalho de Juana Elbein dos Santos (2008), na década de 1970, um conjunto de pesquisas vem seguindo sua trilha e dando atenção às associações entre ecologia, cosmologia e morfologia na arquitetura e no modo de organização espacial dos terreiros, sobretudo de candomblé, enquanto complexos religiosos (Velame 2015; Evangelista 2015). Também têm se destacado estudos que enfocam a dimensão patrimonial dos locais de culto afro-brasileiro, internos e externos aos templos, bem como o instrumental (ainda consideravelmente limitado) para sua proteção (Lira 2017; Blum et al 2018).

Outra vertente acadêmica, não isolada das anteriores, explora as relações de tradição e contradição dos terreiros com a cidade e os espaços de natureza em distintas escalas. Aqui merecem relevo as teses pioneiras de Muniz Sodré - o qual, ao projetar o terreiro como "território político-mítico-religioso", atesta que "pouco importa a pequenez (quantitativa) do espaço

tais unidades sociopolíticas não prefiguram a morte do Estado-nação, ao contrário, acompanharam a sua subida e continuam constituindo-o dialeticamente" (Matory 1999: 70-71). 
topográfico do terreiro, porque ali se organiza, por intensidades, a simbologia de um Cosmos" (Sodré 1988:50-52) - e de Vagner Gonçalves Silva (1995). É provocativa a sugestão deste último de que orixás da/na metrópole, reciprocamente, propulsionam e propiciam uma metrópole de orixás, ou, noutros termos, de que "sendo possível encontrar nos terreiros as marcas do urbano, o movimento no sentido contrário também poderá ser realizado mostrando, na cidade, as referências estabelecidas pelos fiéis no culto aos orixás" (Silva 1995:197).

Compreender os laços que se atam entre terreiros, conformando redes de parentesco e afinidade entre linhagens de axé e "famílias-de-santo", e entre os terreiros e a teia urbana, assentando lugares de axé, faz parte dos empreendimentos teóricos contemporâneos, nas fronteiras disciplinares da antropologia, geografia, urbanismo, biologia (no campo da etnobotânica, por exemplo), entre outros saberes.

Nessa esteira, tomamos como ponto de partida, ao lado de Simas e Rufino (2018), o corpo pensado como terreiro primordial $^{4}$. Especularmente, assim como a pele, fronteira do corpo, as fronteiras dos terreiros são porosas, permitindo e induzindo fluxos entre o "dentro" e o "fora", relacional e não excludentemente imaginados:

A presença do terreiro na cidade é, pois, resultado dessa dinâmica relacional entre o dentro e o fora da religião construída através do diálogo entre dois universos. E, nesse diálogo, entre o candomblé e a cidade, a incorporação dos termos de um universo pelo outro permite que os deuses (e os seus ritos) se transformem para habitar a cidade (como espaço físico e social) e que esta se faça cada vez mais apropriada para recebê-los e protegê-los como parte integrante de seu amplo mercado de bens simbólicos. (Silva 2008:122)

Esta intuição fundamental - a da força do terreiro como "pólo de irradiação" de fluxos territoriais e interações sociais já se achava expressa na etnografia de Santos:

\footnotetext{
4 "Pensar o corpo como terreiro parte da consideração que o mesmo é assentamento de saberes e é devidamente encantado. $\mathrm{O}$ corpo codificado como terreiro é aquele que é cruzado por práticas de saber que o talham, o banham, o envolvem, o vestem e o deitam em conhecimentos pertencentes a outras gramáticas. Tais ritos vigoram esses corpos os potencializando ao ponto que os saberes assentados nesses suportes corporais, ao serem devidamente acionados, reinventam as possibilidades de ser/estar/praticar/encantar o mundo enquanto terreiro" (Simas e Rufino 2018: 50).
} 
O "terreiro" ultrapassa os limites materiais (por assim dizer pólo de irradiação) para se projetar e permear a sociedade global. Os membros do egbé circulam, deslocam-se, trabalham, têm vínculos com a sociedade global, mas constituem uma comunidade "flutuante", que concentra e expressa sua própria estrutura nos "terreiros". (Santos 2008:33)

É dizer, os terreiros e seus membros fiam uma teia urbana própria, que enreda lugares mapeados segundo as bússolas topofílicas ${ }^{5}$ de diversas matrizes africanas. Tais espaços estão vinculados a divindades, ancestrais e outras agências que, a tempo e modo variáveis, devem ser mobilizadas: matas, mares, rios, cachoeiras, pedreiras, cemitérios, linhas férreas, estradas, encruzilhadas e até igrejas. Seu uso ritual encontra-se atualmente ameaçado por conflitos socioambientais cujo acirramento é sensível nas últimas décadas, sendo objeto de vários tipos de mapeamentos (Fonseca e Giacomini 2013).

Todavia, como levar a cabo investigações dessa natureza - mapeamentos, ainda que participativos, cartografias, ainda que sociais - sem reproduzir os regimes de subalternização e invisibilização dos saberes nativos? Numa paráfrase da notorizada pergunta de Spivak (2010): pode o subalterno mapear? Alinhamo-nos, por um lado, às fundadas suspeitas do próprio povo de terreiro e de outros grupos tradicionais sobre as tecnologias do poder, como os mapas, "vistos correntemente como um discurso político a serviço do estado" (Acselrad 2015:10). Por outro lado, com a crítica epistemológica que alerta para os riscos de tomar o conhecimento "cientificamente" validado - e o saber cartográfico como seu paroxismo - por "verdade", nos abusos da razão ocidental.

Para isto - e para tantas outras coisas - estão Exu, senhor da comunicação e seus "nós"; Njila, que habita encruzilhadas epistêmica; e Ananse, guardiã e narradora de histórias na mitologia ashanti, também tida como um trickster, aquela que nos embaralha, que confunde a vontade de saber, que subverte esquemas convencionados, que nos salva de nosso próprio excesso científico: "precisamos lembrar sempre do papel do bobo da corte ou do trickster para evitar tomar nosso conhecimento como verdade, tornando-nos vítimas de nossa

\footnotetext{
${ }^{5} \mathrm{O}$ conceito de "topofilia" - "o elo afetivo entre a pessoa e o lugar ou ambiente físico" (Tuan 2012:19) -, diz respeito a um conjunto de valores e atitudes frente ao meio ambiente que definem culturalmente os sentimentos de filiação, familiaridade, afeição e apego aos lugares, em oposição direta à "topofobia".
} 
própria loucura (...) uma figura mitológica de uma variedade de culturas: o deus-macaco na Índia, a aranha na África (...)" (Turnbull 2003: 96, tradução livre).

Propomos, aqui, portanto, tensionar os regimes hegemônicos de representação, empregando Ananse Ntontan (a teia da aranha), ideograma adinkra "símbolo de sabedoria, esperteza, criatividade e da complexidade da vida" (Nascimento e Gá 2009: 54-55) para esboçar a territorialidade do axé, conforme a Figura 1:

\section{a teia espacial do povo-de-terreiro}
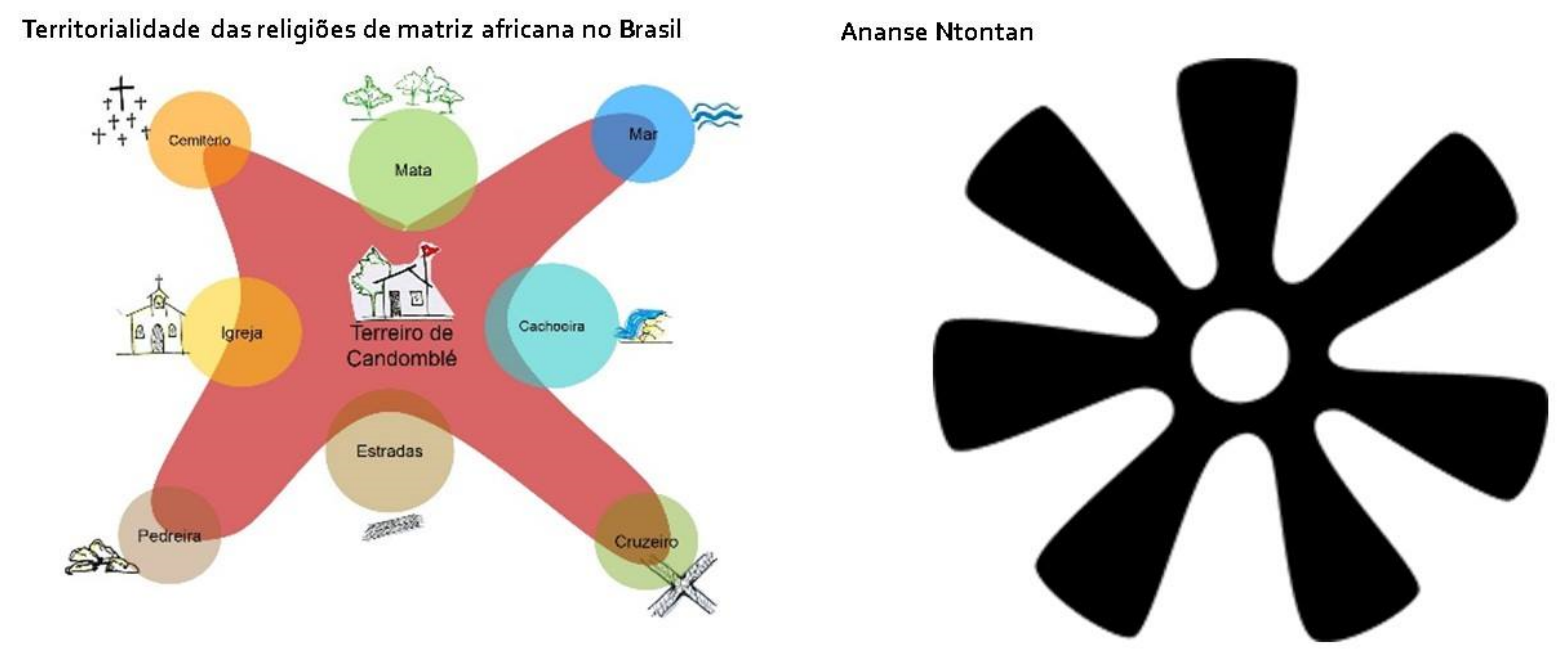

Figura 1: À esquerda, teia espacial do povo-de-terreiro, tecida a partir dos lugares de axé, de uso tradicional mais recorrentes na Triplice Fronteira. À direita, o signo adinkra que representante "a teia de Ananse" na iconografia ashanti. Esquema elaborado no bojo projeto "Os orixás em terras de M'Boi: mapeando os espaços e espacializações afro-brasileiras em Foz do Iguaçu”. (PROEX/UNILA. 2014, coordenado por Andreia Moassab).

Ananse não é só recordada(o) no Brasil. Ela(e) é heroínaherói da resistência não ortodoxa dos afro-colombianos e segue festejada na região do Pacífico, sobretudo no departamento de Chocó, onde a prática da ombligada ("umbigada"6) promove um laço de parentesco espiritual com o território e sua flora. O que

\footnotetext{
${ }^{6}$ A umbigada consiste no enterro do umbigo - cuja ferida é curada com teias de aranha - das crianças aos pés de, ou juntamente, com certas árvores, engendrando um vínculo vitalício de irmandade.
} 
levou Arocha (1998) ao distintivo ombligados de Ananse ("umbigados de Ananse"):

Los ombligados de Ananse son los iniciados en la hermandad de Araña, el dios y diosa de los pueblos fanti-ashanti del golfo de Benín. (...) Como puede caminar por encima y por debajo del agua, llegó a las selvas del Pacífico y por un hilo que fue sacando de su barriga bajó por el manglar a los esteros. Niños y niñas aprenden a imitarla con la complicidad de sus papás, que les ayudan poniéndoles polvos de araña en la herida que deja el ombligo al desprenderse. (...) Ananse es lo que menos tendría que ver con una simple apropiación ambiental. Se trata de un animal que los esclavizados deificaron por su autosuficiencia: del cuerpo teje su vivienda que además usa para procurarse su comida (...) En esta introducción reafirmo que Anansi saca de sus entrañas la red que une a África con América. Paradigma de astucia y supervivencia, Anansi embauca, engaña y crea el caos, pero también reta a deidades más poderosas que ella, de quienes roba el fuego para dárselo a la gente. (Arocha 1998:202-204)

Emprestando e "virando no santo" a expressão cunhada por Arocha, ousamos insinuar que são/estão "enredados(as) de Ananse" os/as sujeitos/as que coletivamente fiam e desafiam marcos, limites e territorialidades num "enredo"7 de lugares, espaços e teias do axé. A complexidade, criatividade e potência inventiva desses processos, dessa lógica territorial, que ritualiza, sacraliza, performatiza a cidade e o mundo, os cosmo/ecologiza e deles se apropria, produz socialmente o espaço vivido como terreiro, ampliando a rede e o enredo do axé para além das fronteiras templo. O terreiro irrompe como devir:

Assim, os terreiros inventam-se, a partir do tempo/espaço praticado, ritualizado pelos saberes e as suas respectivas performances. Essa consideração não despreza a referência dos terreiros a partir de sua fisicalidade, mas alarga o conceito para as dimensões imateriais. (...) O que a noção de terreiro abrange é a possibilidade de se inventar terreiros na ausência de um espaço físico permanente. Assim, abrimos possibilidades para pensar essa noção a partir do rito. (Simas e Rufino 2018:42-43)

\footnotetext{
${ }^{7}$ Categoria nativa ampla do povo de terreiro que expressa a conectividade entre diversas posições, bem como a multiplicidade dos vínculos ancestrais como "heranças de santo", "caminhos cruzados", afetos e afinidades. Ter "enredo" com alguém ou algo é, de alguma forma, participar de uma história em comum.
} 
O terreiro é o mundo em potência e o que denominados de territorialidade do axé é essa potência feita ato ${ }^{8}$, a ultrapassar os muros de um terreno ou edificação e atravessar todo o tecido urbano $^{9}$, inclusive em suas interações e contiguidades com o rural. Essa territorialidade também é, a seu turno, atravessada e reposicionada pelo urbano, em vários sentidos. Trata-se de uma lógica situada do pertencimento, em que um comum imaginado é partilhado, tanto compartido quanto repartido. Ananse Ntontan, a teia espacial, é, pois, emblema de uma determinada partilha do sensível (Rancière 2009) ${ }^{10}$ operada nas e pelas religiosidades afro-diaspóricas.

\section{"Boiadeiros de fronteira" ou o axé como vocação de caminhos}

Se a fronteira, dispositivo territorial do estado-nação, é afrontada no mesmo gesto que a restitui é porque, em certo sentido, faz rizoma, se territorializa na desterritorialização, insinua "linhas de fuga" nas lógicas da regulação (Deleuze e Guattari 2011: 28-29) como parte do modo de (r)existência do santo e do povo de santo. A des/reterritorialização é constitutiva das subjetividades atravessadas que as tradições afro-latinas (porque, no escopo deste texto, já não só afro-brasileiras, mas também afro-paraguaias, afro-argentinas, etc.) assentam e descentram: corpos "feitos de santo" e "no santo" refeitos, móveis moradas que assentam agências transatlânticas.

O caboclo Sete Laços, uma das entidades de Mãe Marina de Ogum, ao identificar-se, na cantiga que serve de epígrafe a este artigo, como "um boiadeiro de fronteira", não deixa de fazer valer sua prerrogativa senão nômade, ao menos caminhante.

\footnotetext{
8 "Ato" é também uma categoria nativa do povo de terreiro que nomina momentos encadeados de uma sequência ritual performática, ou seja, que permitem atar e pôr em ação histórias e devires míticos.

${ }^{9} \mathrm{O}$ conceito de "tecido urbano" é tomado aqui de empréstimo da teoria lefebvriana do urbano (Lefebvre 1999).

${ }^{10} \mathrm{O}$ conceito é utilizado aqui em sua acepção rancieriana: "Denomino partilha do sensível o sistema de evidências sensíveis que revela, ao mesmo tempo, a existência de um comum e dos recortes que nele definem lugares e partes respectivas. Uma partilha do sensível fixa portanto, ao mesmo tempo, um comum partilhado e partes exclusivas. Essa repartição das partes e dos lugares se funda numa partilha de espaços, tempos e tipos de atividade que determina propriamente a maneira como um comum se presta à participação e como uns e outros tomam parte nessa partilha. (Rancière 2009:15)
} 
Essa vocação para os caminhos, esse nomadismo das formas afro-brasileiras já foi interpretada como "possibilidade de organização política sem os riscos de asfixia burocratizante por fixação demasiadamente mecânica numa identidade de grupo", ou seja, "uma forma desterritorializada de fazer política que não deixa de reivindicar direitos e territórios, mas o faz e um modo essencialmente diferente da forma tradicional de se constituir como grupo político" (Dos Anjos 2006:36).

Mesmo disperso, o "gado" de um boiadeiro morador da fronteira, quando convocado, vem ligeiro. Enlaçar, como enredar, é promover amarrações epistêmicas e nós de sentidos e afetos. Será que Seu Sete Laços destina sua chamada aos/as filhos/as espalhados/as hoje em inúmeros países? Em reiterados momentos, eles acolhem o sinal e acodem a casa de origem. Com a substancial expansão do candomblé e da umbanda no Cone Sul, terreiros e famílias-de-santo vêm avançando nos países vizinhos cujas redes, alianças, vínculos e parentescos agregam-se à teia de Ananse, fiando a territorialidade do axé com, contra e à margem da territorialidade estatal.

Por aí há muito que uma "antropologia nas margens do estado" (Das e Poole 2004) poderia fazer. Enquanto isso, caboclos e orixás em trânsito continuarão a visitar corpos em transe $^{11}$, a assentar-se em mercados, cemitérios, encruzilhadas, cachoeiras, praias, estradas, encontros de águas, linhas de trem e casas de santo, "abrindo caminhos" da diáspora sempre em curso como empreendimento inventivo de travessia.

11 "A raiz etimológica da palavra transe nos remete ao latim "transire", formada por "trans" (atravessar) mais "ire" (ir). O caboclo se manifesta pelo transe, pela ideia do ir atravessando como sentido de cruzar mundos, perspectivas, possibilidades práticas, o tempo inteiro. O intransigente é aquele que se nega ao transe. Ao contrário, o transigente é aquele que se dispõe a ele. Todo e qualquer ato criativo só é possível a partir do transe como disponibilidade de travessia. (...) a diáspora é transe. Se vista como traslado apenas, como acontece na maioria das vezes, ela se anula como possibilidade de invenção e apenas afirma a redenção do colonizador e de sua economia fundamentada no sequestro, na objetificação e no comércio de seres humanos. Porém, encruzada a essa perspectiva emerge a noção assente nas macumbas, que compreende um empreendimento inventivo de travessia” (Simas e Rufino 2018:100-101). 
10 | Marina Galdino, Maurício Dos Santos, Thiago Hoshino

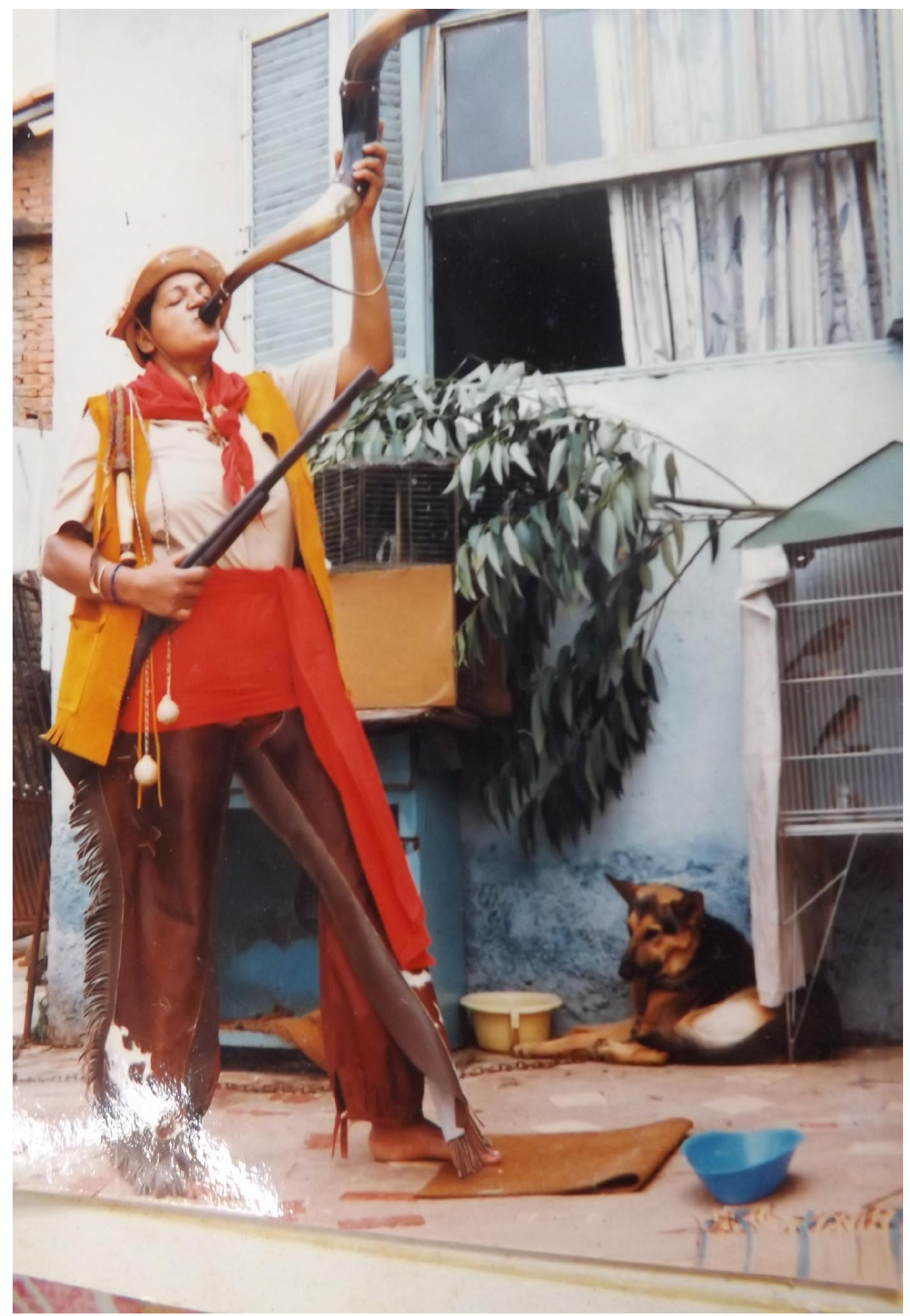

Figura 2: Caboclo Sete Laços. Ile Axé Oju Ogun Funmilaiyó.1994. Arquivo de Mãe Marina. 


\section{Referências bibliográficas}

ACSELRAD, Henri. 2015. "O debate sobre cartografia e processos de territorialização - anotações de leitura”. In: Henri Acselrad; André Dumas Guedes; Maia Laís Jabace. (Orgs.). Cartografias sociais, lutas por terra e lutas por território: um guia de leitura. Rio de Janeiro: IPPUR/UFRJ. p. 08-29.

AROCHA, Jaime. 1998. "Los ombligados de Anansi”. Nómadas (Col) 9:201-209. Bogotá: Universidad Central Bogotá.

BELISO DE JESUS, Aisha. 2015. Eelectric Santeria: racial and sexual assemblages of transnational religion. New York: Columbia University Press.

BHABHA, Homi. 2007. O local da cultura. Belo Horizonte: Editora UFMG.

BLUM, Caroline. et. al. 2018. "Lugares de axé: notas sobre um inventário de terreiros de candomblé em Curitiba e região metropolitana". In: Ana Raggio; Regina Bley e Silvia Trauczynski (orgs.). População Negra no Estado do Paraná: Coletânea de Artigos - Abordagem Sociológica, volume 1. Curitiba: SEJU. p. 248-272.

CARVALHO, José Jorge de. 1999. Um espaço público encantado: pluralidade religiosa e modernidade no Brasil. Brasília: Editoria da UnB.

DAS, Veena; POOLE, Deborah. 2004. Anthropology in the margins of the state. Oxford/New York: Oxford University Press.

DELEUZE, Gilles; GUATTARI, Félix. 2011. Mil Platôs, volume 1. São Paulo: Editora 34.

DOS ANJOS, José Carlos Gomes. 2006. No território da linha cruzada: a cosmopolitica afro-brasileira. Porto Alegre: Editora da UFRGS e Fundação Cultural Palmares.

EVANGELISTA, Daniele Ferreira. 2015. "Fundando um axé: reflexões sobre o processo de construção de um terreiro de candomblé". Religião \& Sociedade 35(1):68-85.

FONSECA, Denise Pini Rosalem da; GIACOMINI, Sonia Maria. 2013. Presença do Axé: Mapeando terreiros no Rio de Faneiro. Rio de Janeiro: Editora da PUC-RJ/ Pallas.

FRIJERIO, Alejandro. 2013. "A transnacionalização como fluxo religioso na fronteira e como campo social: umbanda e batuque na argentina”. Debates do NER 14(23):15-57. 
GOLDMAN, Marcio. 2003. "Os tambores dos mortos e os tambores dos vivos. Etnografia, antropologia e política em Ilhéus, Bahia". Revista de Antropologia 46(2):423-444.

LEFEBVRE, Henri. 1999. A revolução Urbana. Belo Horizonte: UFMG.

LIMA, Vivaldo da Costa. 2003. A família de santo nos candomblés jejes-nagôs da Bahia: um estudo de relações intragrupais. 2. ed. Salvador: Corrupio.

LIRA, Karina Monteiro de. 2017. "Reconhecimento de 'novos' patrimônios: o caso do tombamento do Terreiro Ilê Omo Agboulá - BA". Anais do $1^{\circ}$ Simpósio Cientifico ICOMOS Brasil. Belo Horizonte.

MATORY, J. Lorand. 2015. La religión del Atlántico Negro: tradición, transnacionalismo y matriarcado en el candomblé afrobrasileño. Santiago de Cuba: Casa del Caribe y Editorial Oriente.

MATORY, J. 1999. "Jeje: repensando nações e transnacionalismo". Mana 5(1):57-80.

MEIRA, Thomás Antônio Burneiko. 2017. "As raízes da Nação e as 'nações' da 'raiz': esboço para (mais) uma contrateoria dos sincretismos entre cultos no candomblé". Cadernos de Cатро 26(1):86-110.

NASCIMENTO, Elisa Larkin; GÁ, Luiz Gomes (Orgs.). 2009. Adinkra: sabedoria em símbolos africanos. Rio de Janeiro: Pallas.

ORO, Ari Pedro. 2013. "Transnacionalização religiosa sem migração no cone sul". Debates do NER 14(23):61-72.

RANCIÈRE, Jacques. 2009. A partilha do sensivel. São Paulo: EXO experimental Editora 34.

RISÉRIO, Antônio. 2012. A cidade no Brasil. São Paulo: Editora 34.

SANTOS, Juana Elbein dos. 2008. Os Nàgô e a morte: Pàde, Àsèsè e o culto Égun na Bahia. $13^{\mathrm{a}}$ ed. Petrópolis: Vozes.

SILVA, Vagner Gonçalves da. 2008. "As esquinas sagradas: o candomblé e o uso religioso da cidade”. In: José Guilherme Cantor Magnani; Lilian de Lucca Torres, (orgs.). Na Metrópole. Texto de antropologia urbana. 3 ed. São Paulo: EDUSP. p. 88-123.

SILVA, Vagner Gonçalves da. 1995. Orixás da metrópole. Petrópolis: Vozes. 
SIMAS, Luiz Antonio; RUFINO, Luiz. 2018. Fogo no mato: a ciência encantada das macumbas. Rio de Janeiro: Mórula.

SODRÉ, Muniz. 1988. O terreiro e a cidade: a forma social negrobrasileira. Rio de Janeiro: Vozes.

SPIVAK, Gayatri Chakravorty. 2010. Pode o Subalterno Falar? Belo Horizonte: Editora UFM.

TUAN, Yi-Fu. 2012. Topofilia: um estudo da percepção, atitudes e valores do meio ambiente. Londrina: EDUEL.

TURNBULL, David. 2003. Masons, tricksters and cartographers: comparative studies in the sociology of scientific and indigenous knowledge. London, New York: Routledge.

VELAME, Fábio Macedo. 2015. "Corpos nômades: o cortejo da festa da bandeira em Ponta de Areia". In: Fátima Tavares e Francesca Bassi (orgs.). Festas na Baía de Todos os Santos: visibilizando diversidades, territórios, sociabilidades. Salvador: EDUFBA.

Enviado: 5 de agosto de 2020 Aceito: 11 de novembro de 2020 